as persons, adapting to an environment. Psychiatry must not, as another specialty, worsen this situation. There are particular difficulties inherent in psychology and psychiatry for the student as well as for his teachers, and among these has been the profound influence of the concept of biology as a science based on the causal-mechanical principles of physics. Resistances within the student and within his teachers to approaching the patient as a person are outlined and the historical and cultural origins of some of these are suggested. Current practice in teaching psychology and psychiatry is described and an attempt is made to define a series of objectives for the future.

\section{REFERENCES}

British Medical Students' Association (1959) Report on the Teaching of Psychiatry and Psychological Medicine. B.M.A., London.

Ellis, J. R. (1962). Middx Hosp. J., 62, 229.

Garmany, G., and Whiteley, J. S. (1961).

Romano, J. (1950). J. Amer. med. Ass., 143, 409.

Stengel, E. (1961). Lancet, 2, 418.

Tredgold, R. F. (1962). Ibid., 2, 1344

World Health Organization (1961). Tech. Rep. Ser., No. 208.

\title{
THE TEACHING OF PSYCHIATRY*
}

BY

\author{
JOHN ELLIS, M.B.E., M.A., M.D., F.R.C.P. \\ Physician to the London and Prince of Wales's Hospitals; Secretary to the Association for the Study of Medical Education
}

The medical curriculum has altered much in the past decade. Perhaps the most noticeable change is the very great increase in the amount of time devoted to psychiatry. This subject, both by direct and by indirect means, has grown more extensively in the undergraduate clinical curriculum than has any other, with the possible exception of social medicine. It has not, however, always grown within the teaching hospital itself-and there are some medical schools where the great bulk of this subject is taught by psychiatrists who do not share in the life and work of the medical school, and who do not therefore have any chance of being members of the main teaching team.

This increased emphasis on psychiatry in medical education is a response to a change in medicine. It is difficult to describe, but I suppose it amounts to a new, or perhaps some would claim a revived, interest in the patient as a person, and even as a member of a community. There must now be very few doctors, even in the most mechanical or technical specialties, who think of the patient only as a disease - although, of course, there are many who were never taught to make anything but a disease-label diagnosis, and an organic label at that - and an even larger number whose natural humanitarianism has to operate on less knowledge of human behaviour than many of their patients have obtained from the popular paper-backs.

\section{A New Awareness of Psychiatry}

It must surely be true that almost all doctors now accept that there is mental illness as well as physical, and that both are entitled to medical care. A great many doctors now believe that mental disorder may give rise to physical dysfunction, and there is even a steadily growing number who believe that the pathogenesis of every disease has both a mental and a somatic component.

This very remarkable change in the outlook of the medical profession in this country seems to have come about for two reasons. Firstly, there is the advance which has been made in psychiatry itself: arising from the development of theories of dynamic psychology and psychiatry on the one hand; and on the other from the development of neurophysiology, genetics, and other biological sciences, together with the development of the somatic treatment of psychiatric disturbance. Secondly, there is the increase in the obvious need for psychiatric assistance-both to individuals who have difficulty in adjusting to our rapidly changing environment and to society as a whole, which is faced with precisely the same difficulty.

* Abridgment of a paper presented to the Royal Medico-Psychological Association, London, on November 15, 1962.

D
It must, I think, be admitted that the medical profession's new awareness of psychiatry is based much more upon a realization of the need for it than it is upon any belief that this need can effectively be met. Where this view is held by medical teachers it must, to some extent, offset the value of even a greatly increased amount of teaching of psychiatry. This is particularly important because when one comes to analyse educational objectives in relation to psychiatry it is undeniable that the inculcation in the student of proper attitudes towards it is itself the greatest single objective. Of course the acquisition of knowledge and of skill in the subject are also objectives, though exactly what content of each should be offered to the undergraduate is by no means agreed.

The clinical techniques used in the diagnosis of psychiatric problems do not essentially differ, except in the degree of their refinement, from those used in the diagnosis of any other clinical problems, but the therapeutic skills are such that it is difficult to know to what extent they should be practised by the undergraduate. It is very easy to say that the student should learn how to treat neurosis, and that the treatment of psychosis is a subject for the postgraduate training of the psychiatric specialist. This, however, is merely subdividing the treatment of psychiatric problems among doctors, allotting different parts to different branches. Much neurosis may be less disabling than psychosis and its treatment demand less special facilities, but it does not follow that its treatment is easier, or easily taught to an undergraduate student.

Much the same applies to psychiatric knowledge. It may not be very useful for a general practitioner or a general physician to have detailed knowledge of the psychoses, but it may be much easier for a student to acquire a picture of the most flagrant and classical example of the rarest psychosis than to obtain an understanding of the commonest and mildest neurosis.

After all, a greater proportion of psychiatric knowledge is empirical than is the case in many other areas of medicine. It is based on experience, and psychiatrists seem to disagree rather more than other doctors in their interpretation of this experience. Furthermore, this empirical knowledge is not broken down very extensively into little classified syndromes, each with its own symptoms, course, treatment, and label, as so much of the rest of empirical medicine has been. This, I think, is just as well, but it does not make psychiatry any easier to learn.

Attitudes therefore remain more important, more easily defined, and perhaps more realizable as educational objectives in the undergraduate period than knowledge and skill. But attitudes are as dependent on the other clinical 
teachers as they are on the psychiatrists. This is one reason why complete success in teaching psychiatry can never be achieved simply by increasing the time devoted to it in the curriculum, although on many sides there is constant clamour to do so. Much of this clamour is indeed particularly harmful to the very objectives which it seeks to obtain, for it often gives the impression that medical education consists only of the undergraduate period.

\section{Three Phases of Preparation}

This, of course, was the case for well over 100 yearsbut it is not the case now. The preparation of a doctor consists of three phases-undergraduate, graduate (or preregistration), and postgraduate. Each phase has clear-cut purposes.

The undergraduate phase aims to provide a foundation in method-method of thought and clinical method. It no longer aims to produce a fully prepared doctor of any kind. It does not seek merely to arm a man with to-day's answers to the medical problems of to-day, it seeks to arm him for a dynamic changing future, to provide him with the means of utilizing knowledge rather than with knowledge itself-in a word, to educate him so that he may thereafter learn for himself. To this end it contrives, more than ever before, to enable him to reason, to think critically, to acquire a scientific method of thought. This, which is the main aim of any university education, is now particularly important in medicine, simply because every problem which confronts the doctor is one which consists of somatic, psychological, and social variables. More and more such problems can be solved only by a process of reasoning, and cannot be solved by the operation of a computer-like mental process, which, recognizing in the patient a group of signs and symptoms similar to a cluster of data stored in the memory, provides the diagnosis and treatment which was stored alongside.

The need for every student to learn how to reason, as well as how to recognize (a need which is surely particularly important in psychiatry), is the main reason why doctors can no longer be adequately prepared by a vocational training alone. The fulfilment of this need requires that the student goes into some subject in depth, though the method of thought which he acquires through that subject may thereafter be applied to any other. The curriculum of the undergraduate and the atmosphere in which he works therefore need to be relevant to his education rather than to his future practice. He must still, for obvious reasons, acquire the habit of careful clinical observation and must do so in clinical practice, but it is more important that the hospital atmosphere in which his predecessors trained should be changed to a university atmosphere, than that it should be made identical with general practice or any other practice. The knowledge and skill which is obtained by the undergraduate cannot possibly be comprehensive; it must of necessity vary from student to student. On the other hand, the attitude which he adopts to each individual patient must be a comprehensive one.

In his graduate years, represented now by one preregistration year, the licensed graduate has the opportunity of general comprehensive vocational experience, and this is the main purpose of this period.

In his postgraduate studies each doctor is, or should be, enabled to acquire all of the existing knowledge and skill which is relevant to the practice of a particular branch of medicine.

This preparation in three stages is no idealistic concept. It is fact, though not widely recognized. It is to be seen in existence in America, Russia, Sweden, Britain, and in every country where medical education is developed. In no place is it perfect, and each place would seem to have its own peculiar strengths and weaknesses.

In Britain most of recent criticism has been levelled at the undergraduate medical schools : yet, oddly enough, more has been done to adapt the undergraduate phase than has been done to adapt the others-and done successfully despite the most extraordinary difficulties. One of these has been the failure, for which the universities are not wholly responsible, to make the preregistration year into a proper general vocational training. Another has been the failure, for which the medical schools are not responsible at all, to demand and provide a postgraduate training for general practitioners. Until this is done $50 \%$ of our medical graduates will continue to go into practice without adequate preparation. What is worse, the undergraduate education of all our doctors will continue to suffer, because as no one knows which $50 \%$ of the students will get a seven-year postgraduate training and which will not, the hopeless attempt to give comprehensive coverage to all will inevitably continue. It is strange to think that if to-morrow every executive council and every G.P. decided not to establish a man in practice until he had had an adequate postgraduate training, we would at once set about providing the facilities -and in so doing would immediately ease the manpower situation in both general practice and in hospital-and would be able more easily to make undergraduate education more relevant to modern medicine.

I believe that in the teaching of psychiatry, more than of any other subject, it is essential to bear in mind the three-phase basis of modern medical education.

\section{Some General Considerations}

In undergraduate studies the curriculum is inevitably "personal" to each particular school, deploying its particular strength (of personnel and of facilities) and minimizing its current weaknesses. Therefore abstract estimates of the number of hours to be devoted in an abstract undergraduate curriculum to a particular subject are largely worthless. Indeed, such estimates can be harmful, for they encourage a tendency to think in terms of departmental claims on student-time, and unfortunately evoke ideas of departmental status. They discourage the tendency to think in terms of departmental contribution to the needs of the student. Nevertheless, subject though the extent, nature, and timing of the teaching of psychiatry must be to the particular conditions and curriculum of each school, it is likely in all places also to be subject to certain general considerations, which it is most important to bear in mind. In my view these include:

1. The fact that relatively little psychiatric knowledge is scientifically proved and the empirical knowledge is relatively little classified into labelled syndromes makes psychiatry a diffuse and difficult subject. This can lead to unfortunate comparisons in the student's mind between that firm body of knowledge in other areas of medicine which is easy to learn, and psychiatry which is difficult. The tendency for the results of psychiatric therapy to be slow increases the difficulty and the comparison.

2. The mastery of wide amorphous areas of medical or any other knowledge is difficult at the best of times, amounting almost to learning the unknown, and certainly requiring the acceptance of the unknown. The attempt to achieve this mastery produces insecurity, which often makes the student disinclined to engage in this area. I believe this applies particularly to psychiatry. This insecurity may perhaps best be offset by ensuring that the student first acquires the confidence which comes from mastery of some more simple subject, together with the coincidental acquisition of method of thought, before entering what to him are the more "woolly" fields.

3. For this reason it must be particulariy impurtant in psychiatry to ensure that the maximum incentives to learn are deployed at the time at which teaching is offered. Perhaps experience or responsibility for sick people and personal maturation on a wide basis are needed as incentives. American 
experience of methods to catch the interest of the young in this field has not been very happy. Also, psychology and psychiatry are subjects which carry a particular risk of disturbing the student himself.

4. For all these reasons it is likely that a very important method of teaching in this field is that of apprenticeship. As a medium this has, for various reasons, been translated in British medical education from the undergraduate to the graduate phase.

5. At the present time there is a very serious shortage of psychologists and psychiatrists. It is extremely important that we increase their number by concentrating their attention on the postgraduate training of newly born doctors, whether these have had a good or bad "intrauterine" existence.

6. Concentration on research, with consequent increase in the effectiveness of psychiatry, is also of paramount importance. It may be the one factor which leads to a change in attitude on the part of doctors, of students, and of future applicants for medicine. The fact that $40 \%$ of British hospital beds are occupied by psychiatric patients will never lead students to be as interested in psychiatry as will some therapeutic advance which empties these beds.

\section{The Student's Approach}

These six general considerations should govern the timing of "exposure" of the student to the psychological " component" of medical education. I would suggest that :

1. This exposure must be continuing-from entry to establishment in any particular branch of medicine.

2. Psychology is one of the sciences basic to medicine and should be taught alongside these biological scienceson which it is interdependent and should coincide with genetics and sociology and the other subjects which comprise the "behavioural" sciences. Due attention should be paid to the dangers of teaching the inexact alongside the more exact and of disturbing the immature student.

Concentration should be mainly upon the development of man, and upon the problems of communication. Methods should utilize the fact that the young student is developing as an individual, is a member of a group (or several groups), and is engaged upon the difficult process of learning.

To me it seems logical that these studies should run on into:

3. An introduction to the aetiology of disease which is a necessary prelude to the study of the pathological processes which result from disease.

It is essential that the psychiatrist plays his part in both these areas, and essential that the student comes to realize that psychopathology is no less important, if much less precisely known, than somatopathology.

4. Clinical method, the basic technique of medicine, will presumably be introduced to the student at about this stage and will continue to be practised during the undergraduate period. Its introduction requires the assistance of the best and most experienced teachers of psychiatry, and its further practice will benefit from their continuing interest.

5. As the student continues to practise the methods of obtaining information from patients, he must inevitably engage progressively in the practice of interpreting the evidence and the collection of medical knowledge. In this largest block of undergraduate clinical studies the student must acquire a holistic approach to the patient. and learn how to apply reason to problems consisting of somatic, psychological, and social variables. The extent to which he succeeds will surely depend on each and every clinical teacher. Interdepartmental teaching of various kinds, in most of which a psychiatrist will be needed, can help, but cannot provide the main guidance. The psychiatric department, however, must be wholly responsible at some time in this stage for the introduction of the student to that knowledge which relates specifically to psychiatry. It may well be best to concentrate first and mainly on the psychoses, using the most flagrant and classical examples that can be found.

6. In the graduate period a more secure and mature student engages in responsibility for patients under supervision ; being enabled to do so by his licence, and enabled to profit from doing so by his previous education in method of thought balanced by his facility in clinical method. This is the stage of apprenticeship, and he should be apprenticed to those general doctors, in hospital and outside it, who are capable of practising (or at least are required to try to practise) that holistic approach to the patient which it is intended to engender in the graduate. During this stage it should be possible to give more formal education from the psychiatric department to small groups of interns, concentrating now more upon the problems of neurosis and minor psychological disturbance than upon the psychoses. It is at this stage, 1 believe, that for the first time the average young man becomes really interested in psychiatry and can really begin to comprehend it. The psychiatric specialist can be immensely effective if both the intern and the intern's patient come to him together for specialist advice, both returning together to the general doctor in charge. At this stage, also, the licensed student becomes more aware of the fact that his patient is a member of a group, a family, a factory, and indeed of society as a whole. The student is thus ripe to receive help in understanding social and preventive medicine as a real rather than an abstract entity.

7. The postgraduate student has the simple objective of learning the knowledge and skills relevant to a particular branch of medicine. In the case of psychiatry he is mainly dependent upon psychiatrists: in the case of general practice he needs much help from psychiatrists ; in the case of all other specialties he can benefit from some help from psychiatrists.

In this outline more opportunities exist for contributions from psychiatrists than there are psychiatrists available to make them, especially considering the need for research and the current clinical load placed on psychiatrists because of the psychiatric inadequacies of "organically" trained doctors.

\section{First Priority}

It is surely imperative that first priority be given to postgraduate training (of psychiatrists and of G.P.s), and to all graduates so that the inevitably small amount of seed shall fall upon the most fruitful soil. Priority must also be given to psychology and the introduction to clinical method. Between these two extremes, of late and early teaching, much must be left to the clinicians, especially the general clinicians.

These are not, it has to be admitted, fully equipped for this task. Whether or not they will rapidly become so depends, I believe, on the speed with which psychiatry can be adequately represented in their midst. When university hospitals have full psychiatric units, adequately supported with beds and appropriately equipped for research, then and then only will the continuing education in psychiatry of all clinical teachers be possible. These units and their 
beds are more important to the doctors than to the students in the university centres.

In the final analysis, of course, the teaching, the learning, and the practice of psychological medicine all come down to a matter of time. The practice of medicine can move only in one of two directions-it must become more psychological or it will become a technology. The value of medicine to the community and the status of medicine as a profession both depend on its becoming psychological medicine: but this is much slower to practise than was the organic medicine of thirty years ago, and this simple fact has yet to be reflected in either medical education or the arrangements for medical care. At the moment the timing of medicine is geared to the quick precise diagnosis and treatment of organic disease-yet this is not really the major challenge which medicine in this country has to face.

I think it is true also that in regard to status within the profession we have developed wrong values. The central, main, or father figure is at present the specialist-served by more general auxiliaries. I believe that we desperately need to establish as our father figures generalists who can keep a sense of perspective and reduce vastly complicated issues to their basic essentials. Such men will never be numerous, they may be general from the start or they may be made into "generals" after specialist experience, but inevitably their formation will be greatly dependent upon psychology and psychiatry.

\section{Summary}

The preparation of all doctors needs to be improved so far as psychology and psychiatry are concerned.

What has to be learned includes an attitude of mind, knowledge, and skills. The first is particularly important and is as dependent on all other teachers as it is on psychiatrists. The knowledge is diffuse, largely empirical. and not broken down into described syndromes which can be easily memorized. It is more difficult to acquire than data about organic disease, and the comparison may lead to loss of student interest. The skills are not essentially different from those in general use in medicine, but the younger student is seldom able to acquire them by participation.

"Exposure" to these subjects should not be limited to the undergraduate period of medical education but should be spread through the graduate and postgraduate stages also. What is presented in each stage should be that which the student can assimilate by virtue of his previous knowledge and experience, and must be appropriate to his aims, incentives, and maturity at each stage.

\title{
INTEREST OF GRADUATING MEDICAL STUDENTS IN SOCIAL AND EMOTIONAL ASPECTS OF ILLNESS*
}

BY

\author{
H. J. WALTON, M.D., D.P.M. \\ Nuffield Senior Research Fellow
}

J. DREWERY, M.A. Lecturer in Psychology

\section{G. M. CARSTAIRS, M.D., F.R.C.P.Ed., D.P.M.}

Professor of Psychological Medicine

\section{University of Edinburgh}

\section{Contribution of Psychiatric Teaching to Medical Training}

Concern is felt, both in Britain and in the U.S., that doctors are being trained who are poorly equipped clinically to deal with psychological aspects of illness (College of General Practitioners, 1958; Hill, 1960 ; Schumacher and Gee, (1961), and who show little interest in social and emotional factors in illness (Martin, 1957). An apparent decline takes place in students" "humanism" as medical training progresses (Merton, Bloom, and Rogoff, 1956) ; an initial learning "in order to know" gives way to a narrower aim to satisfy the professional examiners (Becker, Hughes, Geer, and Strauss, 1961).

Psychiatrists have been concerned in numerous educational experiments to foster a "comprehensive" medical orientation in students (Ham, 1959 ; Hammond and Kern, 1959). However, psychiatrists and psychiatry have not been unequivocally acceptable to medical students. Students rarely choose psychiatrists as career role models (Caplovitz, 1960). They tend to rank psychiatry low among the branches of medicine (and their teachers do likewise): in a study of 15 representative U.S. medical schools (Reader, 1958) only dermatology was found to rank lower in prestige. In Britain, only $1 \%$ of clinical students at one school appeared to be interested in a psychiatric career (Richardson, 1962); a more general estimate, from

*This inquiry is part of a continuing study of the effects on medical students of a change in the psychiatric teaching programme being sponsored by the Nuffield Foundation.
2,234 students in five British medical schools (Martin and Boddy 1962), indicates $7 \%$ of students entertain a career preference for psychiatry.

The effects of a psychiatric teaching programme on medical students are uncertain unless the students are evaluated to see if the goals specified by their teachers have been achieved. Measuring changes in students is an arduous undertaking, largely because reliable evaluative instruments for measuring change in knowledge, clinical skills, and attitudes are only now being developed (Langsley, 1962). Even in general medicine examinations are disappointingly unreliable (Hubbard, 1960). Major changes in a teaching programme may not result in any measurable improvement in the students taught by the new method (Aldrich and Bernhardt, 1961). Lecturers know impressionistically that different years of students are dissimilar, but there has been little investigation yet of group variables in classes of medical students, which may foster or impede the aims in teaching a course.

Medical educators have complex issues before them when considering what contribution the teaching of psychiatry should make in the training of all doctors, particularly in view of the changing nature of medical practice. The responsibility to determine objectively the effects on students of a psychiatric teaching programme cannot be waived on the score that convenient measuring devices are not yet available. This investigation reports some effects which psychiatric training had on one class of medical students. 